\title{
Understanding business analytics continuance in agile information system development projects: an expectation- confirmation perspective
}

\author{
Ransome Epie Bawack \\ TBS Business School Research Center, Toulouse Business School, \\ Toulouse, France and \\ TSM Doctoral Programme, Toulouse 1 University Capitole, Toulouse, France, and \\ Muhammad Ovais Ahmad \\ Department of Computer Science and Mathematics, Karlstad University, \\ Karlstad, Sweden
}

\begin{abstract}
Purpose - This paper seeks to examine how expectations from business analytics (BA) by members of agile information systems development (ISD) teams affect their perceptions and continuous use of BA in ISD projects. Design/methodology/approach - Data was collected from 153 respondents working in agile ISD projects and analysed using partial least squares structural equation modelling techniques (PLS-SEM).

Findings - Perceived usefulness and technological compatibility are the most salient factors that affect BA continuance intention in agile ISD projects. The proposed model explains $48.4 \%$ of the variance for BA continuance intention, $50.6 \%$ of the variance in satisfaction, $36.7 \%$ of the variance in perceived usefulness and $31.9 \%$ of the variance in technological compatibility.

Research limitations/implications - First, this study advances understanding of the factors that affect the continuous use of BA in agile ISD projects; second, it contextualizes the expectation-confirmation model by integrating technological compatibility in the context of agile ISD projects.

Originality/value - This is the first study to investigate BA continuance intention from an employee perspective in the context of agile ISD projects.
\end{abstract}

Keywords Business analytics, Information system development, Agile project, Expectation-

confirmation model

Paper type Research paper

\section{Introduction}

In the past few years, there has been a significant rise in the adoption of business analytics (BA) in business organizations (Nam et al., 2019a). These organizations seek to leverage BA to maximize business value and gain a competitive advantage (Wang et al., 2019; Wixom et al., 2013). Consequently, researchers have shown a keen interest in the value BA can create for organizations (Chen et al., 2012; Mikalef et al., 2020; Seddon et al., 2017). Today, BA is essentially the use of statistical models and advanced algorithms to derive business insights from data to support decision making. Although BA has been shown to help improve firm

(C) Ransome Epie Bawack and Muhammad Ovais Ahmad. Published by Emerald Publishing Limited. This article is published under the Creative Commons Attribution (CC BY 4.0) licence. Anyone may reproduce, distribute, translate and create derivative works of this article (for both commercial and non-commercial purposes), subject to full attribution to the original publication and authors. The full terms of this licence may be seen at http://creativecommons.org/licences/by/4.0/legalcode

continuance in agile ISD projects

Received 5 October 2020 Revised 25 November 2020 18 January 2021

Accepted 18 January 2021 
ITP 34,6

agility and performance (Ashrafi et al., 2019; Chiang et al., 2018), little is known about the factors that promote or inhibit the value of BA investments (Mikalef et al., 2020). Furthermore, current studies mostly focus on BA tools and pay little attention to their users or context in which it is used (Conboy et al., 2020; Mikalef et al., 2019). Yet, there is evidence that maximizing the value of $\mathrm{BA}$ investments requires the pervasive use of $\mathrm{BA}$ by employees which entails meeting their expectations regarding aspects like speedy insights, visualization, mobility and user engagement (Wixom et al., 2013). Against this backdrop, this paper seeks to examine how expectations from BA by members of agile information systems development (ISD) teams affect their perceptions and continuous use of BA.

The information systems (IS) discipline has accumulated a significant body of knowledge on ISD project failure and success (Baghizadeh et al., 2020; Jenkin et al., 2019; Saba et al., 2018). Due to increasing demands and high expectations from business organizations in terms of delivery time and output quality, ISD agility has become an unavoidable part of ISD projects (Börjesson and Mathiassen, 2005; Griva et al., 2020; McAvoy et al., 2013). Also, employees in ISD projects show more motivation and job satisfaction when agile project management and software development practices are used (Tripp et al., 2016). Thus, practices that can make ISD projects more agile are essential for ISD teams (Larson and Chang, 2016). Agile ISD projects are increasingly using BA due to its assimilation to increased productivity, better collaboration, improved service quality and enhanced decision making (Wixom et al., 2013). This is essential for project success given the importance of collaboration and mutual understanding among key stakeholders across and within ISD projects (Jenkin et al., 2019; Liu et al., 2018).

However, little is known about what employees in ISD projects expect from BA and the effect this has on their desire to continue using BA. Understanding the relationship between these factors could reveal latent project situations that are difficult to identify, resolve and understand in ISD projects, which may lead to project failure (Baghizadeh et al., 2020; Ochara et al., 2014). This includes issues like misfits between BA and organizational values, and dissonance between stakeholders regarding expectations and outputs. Understanding user expectations has proven to be an effective means of assessing and predicting IS success or failure and the continuance of IS use (Bhattacherjee, 2001; Szajna and Scamell, 1993). Therefore, this study seeks to answer the question: what are the factors that affect $B A$ continuance in agile ISD projects? To answer this question, the expectation-confirmation model (ECM) (Bhattacherjee, 2001) was used as the theoretical framework to hypothesize on the behaviours of employees in agile ISD projects vis-à-vis their expectations from BA investments made by their organizations. Data was collected from 153 respondents working in agile ISD projects and analysed using partial least squares structural equation modelling techniques (PLS-SEM). The results show that expectation confirmations regarding perceived usefulness and technological compatibility are key determinants of BA continuance in agile ISD projects.

This study contributes to calls for studies on how BA can support the management of ISD projects (Dennehy et al., 2020; Elhoseny et al., 2020). Specifically, it makes two main theoretical contributions: (1) this study advances understanding of the factors that affect the continuous use of BA in agile ISD projects; (2) it contextualizes the ECM model by integrating technological compatibility in the context of agile ISD projects. It also contributes to practice by highlighting the importance of managing user expectations during BA projects to ensure BA continuance in ISD projects.

\section{Theoretical background}

\subsection{Business analytics}

$\mathrm{BA}$ refers to the analytical component of business intelligence (BI), that is, the analytics and reporting processes and technologies used in BI (Chen et al., 2012). BI is the process of 
combining insights from data with business knowledge to support decision-making processes (Larson and Chang, 2016). Today, BA spans several technical areas including (big) data analytics, text analytics, web analytics, network analytics, social media analytics and mobile analytics. All these areas rely on data mining, statistics and artificial intelligence (AI) techniques like machine learning (ML) and natural language processing (NLP) (Chen et al., 2012; Larson and Chang, 2016). BA investments are very resource-intensive and risky (Wang et al., 2019). Thus, value is the most important of all the Vs used to characterize (big) data used for BA (Acito and Khatri, 2014; Ashrafi et al., 2019; Fosso Wamba et al., 2015). Business organizations need to capitalize on the value generated from speedy actionable insights and the pervasive use of BA by employees (Wixom et al., 2013) to gain competitive advantages, enhance firm performance and create strategic value. This value is created by uncovering hidden knowledge, improving decision making and supporting strategic planning based on data (Chae, 2014; Chiang et al., 2018). Furthermore, maximizing value from BA investments requires aligning strategy and desirable behaviours to business performance management in conjunction with analytic tasks and capabilities (Acito and Khatri, 2014, p. 566). Analytical tasks include producing, consuming or enabling the creation of insights while capabilities refer to the tools, methods and technologies that support decision making, data analysis and information management.

Recent studies have mostly focused on how BA adoption affects competitiveness, agility and firm performance. Firm agility refers to the ability of a firm to quickly sense changes in an environment (opportunities or threats) and adapt to such changes quickly enough to take advantage of the situation (Ashrafi et al., 2019; Kitchens et al., 2018). BA improves firm agility by enhancing information quality and innovative capabilities (Ashrafi et al., 2019). Highquality information will enable firms to better sense changes in their environments and enable them to make timely decisions needed to adapt to the changes. BA provides such timely information, allowing firms to innovatively adapt to changes and outsmart their competitors. Firm agility enhances firm performance, especially in technologically turbulent environments. The adoption of BA has no direct effect on firm performance but it helps improve business process performance which in turn influences firm performance (Aydiner et al., 2019). However, analytics resources (analytics technology assets and BA capabilities) have a direct effect on business performance (Krishnamoorthi and Mathew, 2018). The relationship between BA and firm performance is mediated by business process change (Torres et al., 2018).

Nevertheless, the adoption of BA depends on technological, organizational or environmental factors related to individual perceptions within the organization and could vary with the stage of adoption. Technological factors (data infrastructure, data quality management) influence all stages of the innovation diffusion process, organizational factors (managerial obstacles, analytics centralization) influence the adoption and assimilation stage, while environmental factors (competition intensity) influence the initial stage (Nam et al., 2019a). IT competence (IT infrastructure, IT business spanning, IT proactive stance) influences data management capabilities (data quality, data integration) which then affects the use of BA for customer relationship management (CRM) and eventually the CRM performance (Nam et al., 2019b). Meanwhile, BA competency and organizational absorptive capacity influence BA assimilation which in turn helps firms improve competitive advantage (Wang et al., 2019). This confirms that firms can only benefit from their BA investments if their users adopt and use them effectively (Jaklič et al., 2018).

However, aligning BA processes and software with the work styles, changing needs and expectations of users is a challenge that affects user perceptions of how well BA fits their jobs. Compatibility directly affects the intention to use BA and mediates the effect of performance perceptions on intention to use. However, the issue of how well BA fits with user expectations has not been thoroughly researched (Jaklič et al., 2018). This line of thought has led to several calls for studies that can help researchers and practitioners understand the behavioural 
ITP 34,6

decisions of BA users regarding the (continuous) use of BA in organizational contexts (Dennehy et al., 2020; Elhoseny et al., 2020). This is the research gap this study seeks to fill by examining what employees in agile ISD projects expect from BA and how this affects their intentions to continue using the BA technologies adopted by their organization.

\subsection{Agile information system development projects}

The IS discipline has accumulated a significant body of knowledge on ISD that significantly complements ISD literature in software engineering and project management disciplines (Hassan and Mathiassen, 2018). A major organizational concern today is the failure of ISD projects. However, the extant literature pays little attention to the conditions and situations that occur during ISD projects that lead to their failure (Baghizadeh et al., 2020). Understanding such conditions and situations could lead to early detection and timely responses towards avoiding project failures. A mutual understanding between key project stakeholder groups regarding project planning and control mechanisms is critical for project success (Jenkin et al., 2019). Furthermore, control type, control degree, control style and control execution affect the development of mutual understanding between the stakeholders (Gregory et al., 2013). ISD projects are inherently complex because they involve dealing with organizational and technological issues (Benbya and McKelvey, 2006; Xia and Lee, 2005) like increasing dependence on a particular IS or limited IT infrastructure to accommodate evolving technologies. Furthermore, there are considerable inherent risks in ISD projects regarding differences between expectations and perceptions which are specific to each actor's knowledge, goals and values (Öbrand et al., 2019). Coping with diversity, knowledge and structure are the most persistent problems and challenges faced by developers in ISD projects at the organizational, environmental and individual levels (Bergvall-Kåreborn and Howcroft, 2014).

A growing methodological approach adopted in ISD projects today is the agile methodology. ISD agility is the continual readiness of an ISD method to rapidly or inherently create change, proactively or reactively embrace change and learn from change while contributing to perceived customer value (economy, quality and simplicity), through its collective components and relationships with its environment (Conboy, 2009, p. 340). This methodology was developed to overcome challenges related to change management, project visibility, transparency, productivity, time-to-market and cost reduction in fast-paced project environments (Alaa and Fitzgerald, 2013; Baham et al., 2017; Kautz, 2011). In ISD projects, agile methodologies can be used for project management and software development practices. In either case, this methodology positively affects employees' perceptions of job satisfaction and job characteristics like job autonomy and task significance (Tripp et al., 2016; Werder and Maedche, 2018). Team diversity, team capabilities, team perceptions, project communication, project technology and project setting are categories of knowledge sharing risks across agile software development teams (Ghobadi and Mathiassen, 2017). Within these teams, project managers are more concerned about project setting barriers while other team members like developers, testers and user representatives are more concerned about project organization and team capability barriers (Ghobadi and Mathiassen, 2016; Taylor, 2016).

Regarding BA usage in ISD projects, current literature mostly focuses on the role of agile methodologies in BA projects. It mostly examines how organizations have successfully adopted agile principles and practices in their BI/BA projects, and how this has altered agile methodologies (Larson and Chang, 2016). The agile principles and practices used for ISD align with the nature of BA projects and significantly decrease the chances of project failure (Larson, 2019; Vidgen et al., 2017). This has led to the creation of a development style called agile analytics, which describes how agile principles and practices can lead to agility in $\mathrm{BI}$ projects (Collier, 2012). To successfully implement agile analytics, a strong customer involvement, a methodical project definition process and effective agile implementation 
methods are required (Batra, 2018; Kisielnicki and Misiak, 2016; Tsoy and Staples, 2020). Nevertheless, BA and agile methodologies when used together improve the productivity of ISD teams. It can support every step of the ISD life cycle, including code repository analytics, project management analytics and application usage analytics (Biesialska et al., 2020). It also helps ISD projects achieve greater agility through improved speed and flexibility (Stodder, 2013). For example, it makes translating business requirements into BA products and services much easier and faster for agile ISD teams than for teams that do not use agile methodologies (Wixom et al., 2013). Nevertheless, no research examines the reasons why ISD project members would continue using.

\section{Research model and hypotheses}

The rationale behind this study is the rising need to manage big data required to provide actionable insights needed to meet the complex and changing needs of business customers when managing ISD projects. With the rising adoption of BA software in ISD projects as well as the increase in project failure (Shah et al., 2019), it is important to investigate the factors that affect BA continuance in ISD projects. ECM is used to investigate BA continuance intention in agile ISD projects because the model theorizes on the cognitive beliefs that influence users' intentions to continue using IS (Bhattacherjee, 2001). Understanding IS user expectations and their effects on user perceptions of performance (decision quality) and satisfaction (with the IS) has been of interest to IS research since the 90s (Szajna and Scamell, 1993). Based on this accumulated body of knowledge on the expectation-confirmation theory (ECT), an ECM was proposed. ECM suggests that the intention to continue using IS is determined by the user's satisfaction with the system and the perceived usefulness of the continued use of the system. However, the user's satisfaction with the IS is influenced by the confirmation of expectations before system use and the perceived usefulness of the system. In ECM, perceived usefulness represents the expected (performance) benefits of IS use (post-implementation) while confirmation represents the perception of congruence between expectations and actual performance. Since its existence, ECM has been extended and validated in several contexts like online shopping and healthcare (Brown et al., 2014; Gupta et al., 2020; Wang et al., 2020; Wu et al., 2020). This shows that ECM forms a solid theoretical foundation that can be used to explain the expectation-confirmation behaviours of IS users at the organizational level.

$B A$ continuance intention is the extent to which a user intends to continue using BA. ECM suggests that the intention to continue using IS is mainly determined by the user's satisfaction with prior system use (Bhattacherjee, 2001). Satisfaction refers to the extent to which a user feels affected by the prior use of a system (Bhattacherjee, 2001). This association has been confirmed several times in the extant literature. Studies show that prior satisfaction with technology positively affects a user's intention to continue using the technology (Cheng, 2020; Gupta et al., 2020). Similarly, in agile ISD projects, we expect employees to intend to continue using BA if they are satisfied with the BA tools and processes adopted for their projects. Figure 1 summarizes the proposed conceptual model for BA continuance in agile ISD projects.

Therefore, we hypothesize that:

H1. User satisfaction with BA use will have a positive effect on BA continuance intention.

Confirmation refers to the degree to which a user perceives the actual performance of a system to match their anticipated performance levels after using the system (Bhattacherjee, 2001). Confirmation of expectations is a key determinant of user satisfaction. The more user expectations from a system are confirmed, the more satisfied they are with the system and vice versa (Bhattacherjee, 2001). This association has also been empirically confirmed in several studies (Brown et al., 2014; Cheng, 2020; Zheng, 2019). We argue that this is also true in agile ISD projects. Given that agile ISD projects seek effective and efficient ways of quickly 
ITP

34,6

\section{6}

Figure 1 .

A proposed conceptual model for BA continuance in agile ISD projects

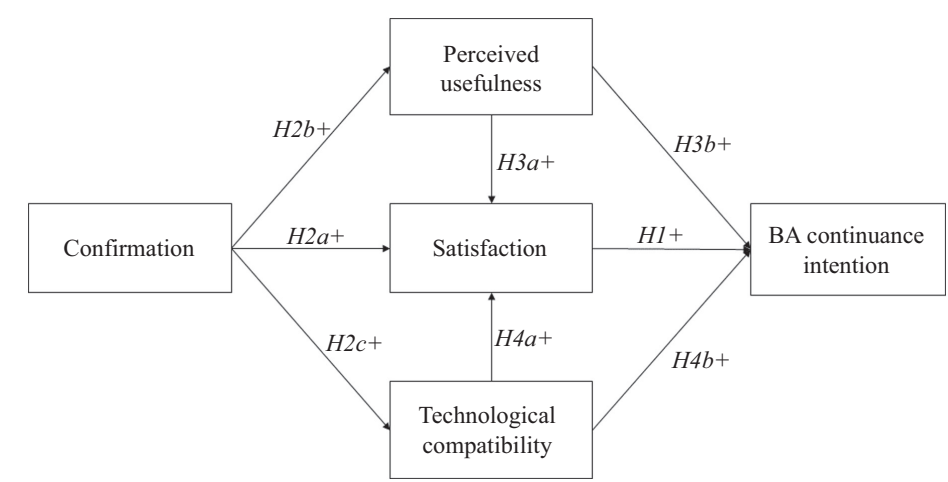

adapting to changing environments while providing business value (Conboy, 2009), satisfaction with BA in an agile ISD project means employees must perceive these abilities when using BA tools and processes. Also, since people form intentions to use a system if they believe it will help enhance their job performance, ECM ascertains that perceived usefulness influences the IS continuance (Bhattacherjee, 2001). This implies that employees will continue using BA tools and processes as long as they perceive it to be useful for their jobs. Moreover, if managers expect the use of BA to be highly beneficial for their teams, they are more likely to invest the necessary resources to make sure it is perceived as beneficial for its users (Chana and Chong, 2013; Chen et al.,2015). Moreover, organizations are shown to be more likely to use $\mathrm{BA}$ if it is found compatible with their existing organizational values and work practices (Chen et al., 2015). Therefore, we hypothesize that:

H2a. Employee confirmation will have a positive effect on satisfaction with BA use.

$H 2 b$. Employee confirmation will have a positive effect on the perceived usefulness of BA use.

H2c. Employee confirmation will have a positive effect on technological compatibility.

Perceived usefulness or expected benefits refers to the extent to which one expects to gain an operational or strategic advantage from using IS (Bhattacherjee, 2001; Chen et al., 2015). Perceived usefulness has been theorized to be the most important expectation influencing user satisfaction with IS. This is because the IS is perceived as an instrument that should enhance the performance outcomes of its user (Cheng, 2020). ECM established that user expectations of the perceived usefulness of IS influence their satisfaction with the system. We argue that in agile ISD projects, users will also be satisfied with BA if they perceive it as useful and vice versa. The objectives of analytics in the big data era are evolving from decision support and performance management to data-driven businesses wherein employees are expected to acquire, transform and visualize data quickly, especially when using agile methodologies (Daradkeh, 2019; Larson and Chang, 2016; Mandal, 2019; Persaud, 2020). Thus, employees in agile ISD projects are more likely to perceive BA as useful if it can help them meet their prescriptive and predictive analytics goals through the rapid acquisition, transformation and visualization of data. Therefore, we hypothesize that:

H3a. Perceived usefulness of BA will have a positive effect on satisfaction with BA use.

$H 3 b$. Perceived usefulness of BA will have a positive effect on BA continuance intention.

Technological compatibility refers to the extent to which a technology consistently aligns with the needs, values and past experiences of its user (Chen et al., 2015). Organizations are shown to 
be more likely to use BDA if it is found compatible with their existing organizational values and work practices (Chen et al., 2015). Employees are also more likely to use IS if the data captured by the system matches their current data needs, data processing procedures, organizational values and IT infrastructure (Awa et al., 2017; Rossi et al., 2012). In agile ISD teams, we argue that employees' perceptions of technological compatibility significantly affect their satisfaction with BA use as well as their continuance intentions. Agile ISD projects usually consist of very diverse teams with people from different technical backgrounds and work ethics. For each team member to be satisfied with BA, the BA tools and processes not only need to be aligned with the shared values of the team but also with the individual characteristics and expectations of team members. Thus, the more compatible the BA is with the ISD project teams, the more satisfied they will be with the system. Therefore, we hypothesize that:

H4a. Technological compatibility will have a positive effect on satisfaction with BA use.

H4b. Technological compatibility will have a positive effect on BA continuance intention.

\section{Methodology}

\subsection{Data collection}

To test the proposed research model, an online questionnaire-based survey was used to collect data from employees working in agile ISD projects. This approach was chosen because it is easy to replicate, facilitates the investigation of multiple constructs simultaneously and easy to generalize the results during exploratory studies based on predictive models (Boudreau et al., 2001; Pinsonneault and Kraemer, 1993). Well-established measurement items were used to measure each construct used in the model. All constructs were measured using a 7-point Likert scale. A pre-test was conducted on 20 employees working on ISD projects to assess the face and content validity of the items used in the study as well as the clarity of the questionnaire.

The study was sent to 400 employees working on agile ISD projects in companies in Ireland and Sweden, two of the most globally competitive countries worldwide in terms of productivity (Klaus, 2019). Respondents were contacted either directly through phone calls and emails or via LinkedIn groups. At the end of the questionnaire, participants were also offered the opportunity to comment on the questionnaire and to provide additional comments on their perceptions of BA use, especially regarding their intention to continue/discontinue using BA software or techniques in their projects. The data collection process lasted three months (June 2020-August 2020) and the average completion time of the questionnaire was $10 \mathrm{~min}$. From the 161 responses collected, 153 responses were retained for further analysis.

Table 1 presents a description of the sample. Most of the respondents were from Europe (74\%) from technology-oriented companies including software and services development $(56 \%)$. The remaining respondents work in various business sectors such as IT consulting $(13 \%)$, e-commerce $(9 \%)$ and others.

Summarily, most respondents had at most 4 years of experience with BA (60\%). The respondent has worked in small teams (1-9 (31\%) or 10 to $49(28 \%))$ and occupied mostly team lead $(25 \%)$, developer $(23 \%)$ or business analyst $(18 \%)$ positions (see Table 2 ).

\subsection{Data analysis}

To avoid measurement errors due to common method bias (CMB), the following measures were taken (Podsakoff et al., 2003): (1) questions in the survey were juxtaposed to create a psychological separation of measurements; (2) to ensure that respondents provided honest answers, they were informed that the study was for academic research purposes, their participation will remain anonymous and there were no wrong or right answers; (3) scale items were improved after the pre-test by rewording some terms to make the questionnaire 
Office location

North America

Europe

Australia/New Zealand

Asia

1558

South/Central America

Africa

Other

Business industry

Technology (incl. Software)

Financial services

IT consulting

E-commerce

Government

Manufacturing

Other

Experience in ISD projects

1 year or less

$\begin{array}{rr}85 & 56 \\ 6 & 4 \\ 20 & 13 \\ 14 & 9 \\ 10 & 7 \\ 4 & 3 \\ 14 & 9\end{array}$

2 years

3 years

4 years

Over 4 years

Experience with $B A$

1 year or less

2 years

Table 1.

3 years

demography and 4 years

business sector

Over 4 years 
easy to understand thereby reducing biases related to the ambiguity of items; (4) Harman's single-factor test was performed to determine whether most of the variance in the model can be accounted for by a single factor. The test showed that there is no threat of CMB in this study since the maximum variance explained by a single factor was $28.8 \%$ which is below the $50 \%$ threshold value.

To evaluate the model proposed in this study, partial least squares structural equation modelling (PLS-SEM) approach was used with the help of the SmartPLS 3.2.9 software package. The PLS-SEM approach is a well-established approach used in quantitative research to understand relationships between variables and the predictivity of models in exploratory studies (Hair et al., 2014; Hair et al., 2016; Leguina, 2015). It is a variance-based SEM technique which is more appropriate for exploratory studies where the aim is to examine relationships between variables based on theory (Reinartz et al., 2009). This approach involves two main phases: (1) evaluating the measurement model and (2) evaluating the structural model (Hair et al., 2017).

\section{Results}

This section discusses the results of our study that include the measurement model, the structural model and hypothesis testing.

\subsection{Measurement model}

Evaluating the measurement model involves assessing the reliability and validity of the constructs and their corresponding items. Based on Hair et al. (2016), items are reliable if the item loadings are greater than 0.70 . For constructs to be reliable, they should have composite reliability (CR) and Cronbach's alpha $(\alpha)$ values above 0.60 . To ensure that the constructs significantly explain the variance of its items, the average variance extracted (AVE) should be greater than 0.50. Finally, the Fornell-Larcker criterion can be used to assess the discriminant validity of the constructs. Discriminant validity is verified if the square root of the AVE for each construct is greater than the correlation between the constructs (Fornell and Larcker, 1981).

The items used to measure each construct were obtained from existing measurement scales that have been empirically tested and validated in previous studies (Bhattacherjee, 2001; Chen et al., 2015). Table 3 presents the constructs, their operational definitions, measurement items and the results of the measurement model evaluations. All item loadings, Cronbach's alpha and composite reliability values are greater than the 0.70 thresholds, indicating the reliability of the constructs and items used in the measurement model. Also, all AVE values are greater than the 0.50 threshold value indicating convergent validity.

According to Fornell and Larcker (1981), convergent validity is satisfactory when constructs have an AVE of at least 0.5. Table 4 presents the results of the discriminant validity, which is based on the Fornell-Larcker criterion with correlations, and the square root of AVE values on the diagonal.

\subsection{Structural model}

Evaluating the structural model involves assessing the predictability of the model and the significance of the relationships that exist between variables in the model. According to Hair et al. (2016), there should be no collinearity among the constructs to avoid biasing the regression results. Thus, the variance inflator factor should be less than five to show the absence of collinearity. $p$-values of less than $5 \%$ indicate significant path coefficients between variables. Finally, $R^{2}$ values of $0.75,0.50$ and 0.25 indicate substantial, moderate and weak predictive accuracy of the model respectively. Figure 2 summarizes the results of the PLS structural model analysis. 
BA continuance intention-BA_CI (Bhattacherjee, 2001$)(\alpha=0.792, \mathrm{CR}=0.878, \mathrm{AVE}=0.706)$

The extent to which a user intends to continue using $B A$

I intend to continue using BA rather than discontinue its use $\quad 0.857$

$\mathbf{1 5 6 0}$ I intend to continue using BA than any alternative means 0.851

$\begin{array}{ll}\text { I would like to continue my use of BA } & 0.812\end{array}$

Confirmation-BA_TC (Bhattacherjee, 2001) $(\alpha=0.748, \mathrm{CR}=0.855, \mathrm{AVE}=0.664)$

The degree to which a user perceives the actual performance of $B A$ to match their anticipated performance levels after BA use

My experience with using BA was better than what I expected

The service level provided by BA was better than what I expected

Overall, most of my expectations from using BA were confirmed

0.842

Satisfaction-BA_S (Bhattacherjee, 2001) $(\alpha=1, \mathrm{CR}=1, \mathrm{AVE}=1)$

The extent to which a user feels affected by prior $B A$ use

How do you feel about the overall experience of BA use?

Perceived usefulness-BA_PU (Bhattacherjee, 2001) $(\alpha=0.855, \mathrm{CR}=0.902$, AVE $=0.698)$

The extent to which one expects to gain an operational or strategic advantage from using $B A$

Using BA improves my job performance

Using BA increases my job productivity

Using BA enhances my effectiveness in my job

0.864

Overall, BA is using in my job

0.884

0.836

Technological compatibility $-B A \_T C($ Chen et al., 2015) $(\alpha=0.769, \mathrm{CR}=0.866, \mathrm{AVE}=0.684)$

\section{Table 3.}

The extent to which a BA consistently aligns with the needs, values and past experiences of its user

Reliability and validity Using BA is consistent with our business practices

0.839

Using BA fits our organizational culture

0.854

Overall, it is easy to incorporate BA into our agile practices

0.788

\begin{tabular}{lccccc}
\hline Constructs & BA_CI & BA_C & BA_PU & BA_S & BA_TC \\
\hline BA_CI & 0.840 & & & & \\
BA_C & 0.594 & 0.815 & & & \\
BA_PU & 0.611 & 0.606 & 0.836 & & \\
BA_S & 0.455 & 0.633 & 0.635 & 1.000 & \\
BA_TC & 0.624 & 0.565 & 0.576 & 0.504 & 0.827
\end{tabular}

Table 4.
Discriminant validity (Fornell and Larcker Method)

Note(s): The square roots of AVEs of the constructs are shown in Italic in diagonal. The off-diagonal values are correlations between constructs

Figure 2.

Estimated paths of the structural model

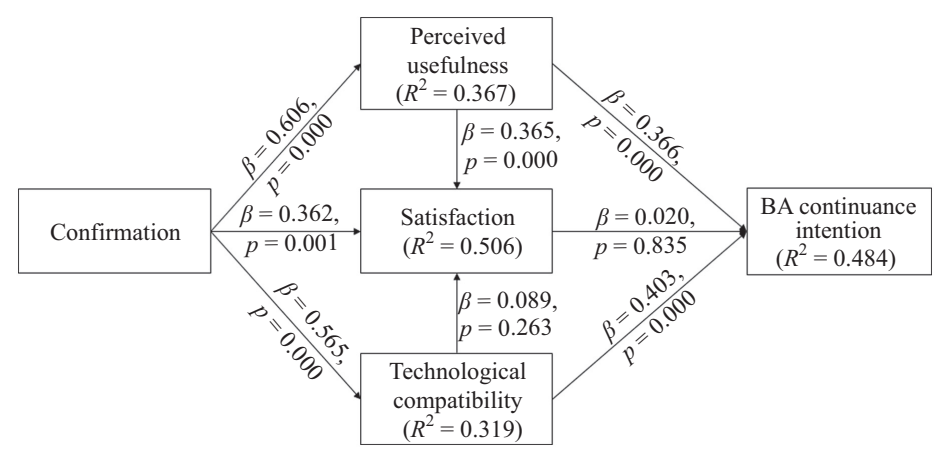


The structural model was evaluated by running 5,000 bootstrap subsamples. There was no collinearity biasing the regression results of our model since the maximum VIF value among all items used in the model was 3.818 , which is below the 5.0 threshold value. Based on $R^{2}$ values, the structural model explains $48.4 \%$ of the variance for BA continuance intention, $50.6 \%$ of the variance in satisfaction, $36.7 \%$ of the variance in perceived usefulness and $31.9 \%$ of the variance in technological compatibility. These coefficients of determination indicate the moderate to substantial predictive power of the model. By analysing the significance of the path coefficients $(\beta)$ using $p$-values $(\phi)$, the model shows that perceived usefulness $(\beta=0.366$, $p=0.000)$ and technological compatibility $(\beta=0.403, p=0.000)$ significantly affect BA continuance. Also, confirmation significantly affects perceived usefulness $\beta=0.606$, $p=0.000)$, technological compatibility $(\beta=0.565, p=0.000)$ and satisfaction $(\beta=0.362$, $p=0.001)$. Additionally, perceived usefulness significantly affects satisfaction $(\beta=0.365$, $p=0.000$ ). Contrary to what was expected, technological compatibility had no significant effect on satisfaction $(\beta=0.089, p=0.263)$, and satisfaction had no significant effect on BA continuance $(\beta=0.020, p=0.835)$. The analysis also shows that perceived usefulness had a mediating effect between confirmation and BA continuance intention $(\beta=0.0 .222, p=0.000)$ and between confirmation and satisfaction $(\beta=0.221, p=0.001)$. Technological compatibility also mediated the relationship between confirmation and BA continuance $\beta=0.228$, $p=0.000)$. Table 5 summarizes the findings of the structural model evaluation.

\section{Discussion}

This study sought to examine what employees in agile ISD projects expect from BA and how this affects their intentions to continue using the BA technologies adopted by their organization. The motivation for this study is that extant research in the area mostly focuses on how BA adoption affects firm competitiveness, agility and performance. Some focus on the successful implementation of BA technologies but pay little attention to its users or context of use (Conboy et al., 2020; Dennehy et al., 2020; Mikalef et al., 2019). Such studies have established that successfully implementing BA requires identifying business needs, building BA teams, identifying talents, identifying skills and certifications needed, involving stakeholders and creating a BA culture (Larson and Chang, 2016; Liu et al., 2018). However, no study explains what would make users continue using BA after successful implementation. Addressing this issue in the specific context of agile ISD projects, this study used ECM to provide a theoretical understanding of the mechanisms that explain this phenomenon. Specifically, the findings of this study reveal that BA continuance is influenced by the confirmation of expectations, perceived usefulness and technological compatibility.

These findings are consistent with existing literature on ECM and highlight technological compatibility as a key technological driver of BA continuance. By showing the effect of

\begin{tabular}{|c|c|c|c|c|}
\hline \multicolumn{2}{|c|}{ Hypothesis } & \multirow{2}{*}{$\frac{\text { Path coefficient }}{0.020}$} & \multirow{2}{*}{$\frac{p \text { values }}{0.255}$} & \multirow{2}{*}{$\begin{array}{l}\text { Hypothesis } \\
\text { validation }\end{array}$} \\
\hline $\mathrm{H} 1$ & Satisfaction - > BA continuance & & & \\
\hline $\mathrm{H} 2 \mathrm{a}$ & Confirmation - > Satisfaction & $0.362^{* * * *}$ & 0.001 & Supported \\
\hline $\mathrm{H} 2 \mathrm{~b}$ & Confirmation - > Perceived usefulness & $0.606 * * *$ & 0.000 & Supported \\
\hline $\mathrm{H} 2 \mathrm{c}$ & Confirmation - > Technological compatibility & $0.565 * * *$ & 0.000 & Supported \\
\hline HЗа & Perceived usefulness - > Satisfaction & $0.365 * * *$ & 0.000 & Supported \\
\hline $\mathrm{H} 3 \mathrm{~b}$ & Perceived usefulness - > BA continuance & $0.366^{* * * *}$ & 0.000 & Supported \\
\hline $\mathrm{H} 4 \mathrm{a}$ & Technological compatibility - > Satisfaction & 0.089 & 0.269 & Not supported \\
\hline $\mathrm{H} 4 \mathrm{~b}$ & $\begin{array}{l}\text { Technological compatibility - > BA } \\
\text { continuance }\end{array}$ & $0.403 * * *$ & 0.000 & Supported \\
\hline
\end{tabular}

$\operatorname{Note}(\mathbf{s}): * * * p<0.01$

\section{BA continuance in agile ISD projects}

1561 
ITP

34,6

1562

expectation confirmation on perceived usefulness, satisfaction and technological compatibility, our findings support existing literature that emphasizes the importance of managing the expectations of BA users. Explaining and managing the expectations of stakeholders remains a major challenge for BA project managers. BA users expect BA technologies to be very robust and highly responsive to user interactions (Larson and Chang, 2016; Viaene and Van Den Bunder, 2011). However, the users do not always get to choose the BA technology adopted for the project, thereby making them develop low initial usefulness perceptions yet to be confirmed as they use the technology. In line with ECM, agile ISD project team members who perceive BA implemented as meeting or surpassing their anticipated expectations would be satisfied with the BA technology and perceive it as useful for their jobs. Furthermore, the team members would continue using the BA implemented if they confirm that it is consistently compatible with their needs, values and past experiences. Thus, our findings confirm the importance of adopting BA technology that is compatible with the culture and practices of agile ISD teams (Chen et al., 2015).

Surprisingly, BA continuance is not affected by satisfaction. However, it is strongly affected by perceived usefulness and technological compatibility. Nevertheless, perceived usefulness affects satisfaction, while technological compatibility does not. In other words, BA users seemed to tell their intentions to continue using BA systems based on their perceptions of usefulness and technological compatibility rather than overall satisfaction. This implies that BA continuance is affected by actual gains in operational or strategic advantage and alignment with user needs, values and work experience rather than overall satisfaction. However, confirmation of expectations and perceived usefulness of BA systems affect user satisfaction as theorized. This implies that the overall satisfaction with the BA system is not affected by the extent to which the system consistently aligns with the needs, values and past experiences of its users. Rather, it is based on the psychological and emotional state of satisfaction derived from the user's confirmation of expectations regarding their subjectively expected standards and performance levels (Yi, 1990). These findings suggest that satisfaction is important to BA users but it is not a reason why they would continue using BA. Furthermore, satisfaction has no mediating effect on BA continuance. Therefore, BA continuance should be regarded as an extension of satisfaction rather than a reason for BA continuance. This is in line with previous studies that show that satisfaction is not always a reason for continuance (Um et al., 2006).

Existing literature suggests that technological compatibility is relevant for managers who decide on technological innovations to be adopted by their organizations (Chen et al., 2015). Since employees generally do not make such strategic decisions, this could explain why technological capability had no significant effect on satisfaction in this study. Nevertheless, technological compatibility remains significant and relevant for BA continuance in agile ISD project teams. This shows that although it does not affect their satisfaction, team members still need the BA to be compatible with their organizational values and work practices. As opposed to predictions made based on ECM, satisfaction has no significant effect on BA continuance in agile ISD projects. This could be because like with many other technologies implemented in organizations (Venkatesh et al., 2012), using BA might be mandatory in agile ISD projects. Thus, team members would have to use the BA technology adopted by the organization whether they are satisfied with it or not. From this perspective, it is obvious that their satisfaction with the BA system does not affect continuance. Rather, objective factors like PU and TC affect continuance. Therefore, it is important to identify other rational and objective factors that influence BA continuance.

To conclude this section, expectation confirmation of the perceived usefulness and technological compatibility of BA technologies are key determinants of BA continuance in agile ISD projects. As opposed to perceived usefulness and technological compatibility, satisfaction is highly subjective. Therefore, BA continuance is highly dependent on rational, 
objective and verifiable factors or arguments such as technological compatibility and usefulness.

\subsection{Theoretical implications}

With the rising adoption of BA software in ISD projects as well as the increase in project failure (Shah et al., 2019), it is important to investigate the factors that affect BA continuance in ISD projects. This study has two major implications for research. First, it uses a theoretical perspective to empirically examine the antecedents of BA continuance. Prior studies have mostly focused on BA adoption and not on its continuous use, even less in agile ISD project contexts (Daradkeh, 2019). This study extends the existing body of knowledge on BA adoption at the organizational level. Specifically, the research model, which is grounded in ECM, is readily applicable and generalizable to future studies on BA continuance. This study also highlights confirmation of expectations regarding the perceived usefulness and technological compatibility of BA as key determinants of BA continuance. However, the methodology used does not explain the nature of the relationship between these factors. Thus, future research should examine the nature of the relationship between the factors and how this affects organizational performance. Also, future research should replicate this study in other ISD environments to determine whether new contexts could reveal new factors that affect BA continuance at the organizational level. Furthermore, this study suggests that technological factors have a direct effect on BA continuance. Thus, future research should integrate complementary theoretical perspectives to further identify factors and explain this phenomenon.

Second, this study contributes to big data research on the potential outcomes of big data initiatives for relevant stakeholders (Abbasi et al., 2016; Mandal, 2019). Specifically, this study assesses the outcomes of BA initiatives in agile ISD projects and its outcomes for project team members. It provides a more holistic understanding of BA continuance in agile ISD projects and the salient factors to be considered at the project team level by explaining how BA contributes to the management of agile ISD projects (Dennehy et al., 2020). By extending the ECM with technological compatibility, this study also provides a more contextualized understanding of the motivations behind the continuous use of BA in agile ISD projects. Thus, it contributes to the understanding of factors in agile ISD projects that lead to project success or failure (Baghizadeh et al., 2020) and how well BA fits with user expectations (Jaklič et al., 2018).

\subsection{Practical implications}

The results of this study also have important managerial implications. Since maximizing the value of BA requires its pervasive use by employees, understanding their expectations is crucial for BA continuance in organizations (Wixom et al., 2013). Furthermore, understanding BA continuance in this context is becoming indispensable as agile processes and methodologies are arguably becoming the norm in ISD projects (McAvoy et al., 2013; Tripp et al., 2016). Thus, this study could serve as evidence of the importance of managing user expectations in BA projects to ensure BA continuance. The results of this study show that $\mathrm{BA}$ project managers need to focus on managing user expectations regarding the usefulness and compatibility of the BA implemented to ensure continuance. Based on existing literature reviewed in this study, these managers should prioritize BA solutions that favour change management, project visibility, transparency, productivity, time-to-market and cost reduction because agile teams work in fast-paced project environments. Furthermore, the findings of this study provide insights for managers on how to assess and ensure BA continuance. In agile ISD projects, for example, agile principles and practices would have to evolve to meet new BA trends like fast analytics and data science (Larson and Chang, 2016). Thus, managers in charge of choosing the BA to be adopted by their 
ITP

34,6

1564

organizations should ensure that the BA chosen is compatible with their organizational values and work practices of the users. Project managers also need to focus on the expectations of BA users regarding the usefulness of the BA for individual tasks, especially how BA would affect their operational efficiency and job performance. Through this approach, managers would be able to identify, resolve, understand and anticipate BA discontinuance, thereby prevent BA project failure. This includes avoiding misfits between the BA adopted, organizational values and work practices.

\subsection{Limitations and future direction}

This study has some limitations which are also opportunities for future research. First, some respondents were LinkedIn contacts and members of groups specialized in BA. Thus, there was limited control over the type of participants. However, such limitations could be alleviated by the fact that respondents worked in different projects, thereby showing significant diversity in our dataset. Second, it is important to consider that respondents were individuals who represented different organizations. Consequently, a single person cannot answer on behalf of the whole business unit/organization. Further, getting respondents from companies was quite challenging especially given the strict criteria of this study that required participants to be part of an agile ISD project and current BA users in the project. Since respondents were current and continuing users of BA, they may also have been biased in their perceptions. Third, this study collected data only at one point in time (cross-sectional study). It would have been ideal to perform a longitudinal study to compare the preacceptance and post-acceptance perceptions of respondents. However, this was too challenging for this study especially given the ongoing coronavirus disease (COVID) pandemic that made data collection very challenging as employees were usually inaccessible and some projects had to close down temporarily. Additionally, a majority of the respondents are from European-based companies. In the future, it would be worth having an in-depth investigation in various companies, countries or business sectors. This would enable a more in-depth analysis of changes in perceived usefulness, technological compatibility and satisfaction over time. These limitations present potential ways of extending the current research and validating our model in other settings.

\section{Conclusion}

This study sought to understand what employees in agile ISD projects expect from BA and how this affects their intentions to continue using the BA technologies adopted by their organization. The results show that ISD project managers need to ensure that their team members perceive the BA system adopted as useful to their jobs and compatible with all other technologies they use to perform their daily tasks. This would help ISD projects to obtain maximum value from their BA investments, especially regarding agility and performance. From a theoretical standpoint, IS continuance is contingent on the confirmation of expectations from its users. While this is broadly recognized in the ISD literature, prior research has not evaluated this claim in the context of BA continuance in agile ISD projects. Consequently, there has been a gap in the existing literature on the success and failure of BA initiatives in ISD projects. Using ECM as a theoretical lens, this study shows that confirmation of expectations regarding perceived usefulness and technological compatibility are key determinants of BA continuance intentions in agile ISD projects. This study contributes to current research efforts towards improving the management of ISD projects using BA, with emphasis on the BA users and the agile ISD context rather than on the BA technology used. Thus, this study is expected to stimulate further research on BA continuance in agile ISD contexts, especially in identifying other rational, objective and verifiable BA continuance factors. 
Abbasi, A., Sarker, S. and Chiang, R.H.L. (2016), "Big data research in information systems: toward an inclusive research agenda", Journal of the Association for Information Systems, Vol. 17 No. 2, pp. 1-32.

Acito, F. and Khatri, V. (2014), "Business analytics: why now and what next?", Business Horizons, Vol. 57 No. 5 , pp. 565-570.

Alaa, G. and Fitzgerald, G. (2013), "Re-conceptualizing agile information systems development using complex adaptive systems theory", Emergence: Complexity and Organization, Emergent Publications, Vol. 15 No. 3, pp. 1-23.

Ashrafi, A., Zare Ravasan, A., Trkman, P. and Afshari, S. (2019), "The role of business analytics capabilities in bolstering firms' agility and performance", International Journal of Information Management, Vol. 47, pp. 1-15.

Awa, H.O., Uko, J.P. and Ukoha, O. (2017), "An empirical study of some critical adoption factors of ERP software", International Journal of Human-Computer Interaction, Taylor \& Francis, Vol. 33 No. 8, pp. 609-622.

Aydiner, A.S., Tatoglu, E., Bayraktar, E., Zaim, S. and Delen, D. (2019), "Business analytics and firm performance: the mediating role of business process performance", Journal of Business Research, Vol. 96, pp. 228-237.

Baghizadeh, Z., Cecez-Kecmanovic, D. and Schlagwein, D. (2020), "Review and critique of the information systems development project failure literature: an argument for exploring information systems development project distress", Journal of Information Technology, Vol. 35 No. 2, pp. 123-142, (Palgrave Macmillan).

Baham, C., Hirschheim, R., Calderon, A.A. and Kisekka, V. (2017), "An agile methodology for the disaster recovery of information systems under catastrophic scenarios", Journal of Management Information Systems, Taylor \& Francis, Vol. 34 No. 3, pp. 633-663.

Batra, D. (2018), "Agile values or plan-driven aspects: which factor contributes more toward the success of data warehousing, business intelligence, and analytics project development?", Journal of Systems and Software, Vol. 146, pp. 249-262.

Benbya, H. and McKelvey, B. (2006), “Toward a complexity theory of information systems development”, Information Technology and People, Emerald Group Publishing, Vol. 19 No. 1, pp. 12-34.

Bergvall-Kåreborn, B. and Howcroft, D. (2014), "Persistent problems and practices in information systems development: a study of mobile applications development and distribution", Information Systems Journal, Wiley-Blackwell, Vol. 24 No. 5, pp. 425-444.

Bhattacherjee, A. (2001), "Understanding information systems continuance: an expectationconfirmation model”, MIS Quarterly, JSTOR, Vol. 25 No. 3, pp. 351-370.

Biesialska, K., Franch, X. and Muntés-Mulero, V. (2020), "Big Data analytics in Agile software development: a systematic mapping study", Information and Software Technology, Vol. 132, p. 106448.

Börjesson, A. and Mathiassen, L. (2005), "Improving software organizations: agility challenges and implications", Information Technology and People, Emerald Group Publishing, Vol. 18 No. 4, pp. 359-382.

Boudreau, M.C., Gefen, D. and Straub, D.W. (2001), "Validation in information systems research: a state-of-the-art assessment”, MIS Quarterly: Management Information Systems, Vol. 25 No. 1, pp. 1-16, JSTOR.

Brown, S.A., Venkatesh, V. and Goyal, S. (2014), "Expectation confirmation in information systems research: a test of six competing models", MIS Quarterly: Management Information Systems, Vol. 38 No. 3, pp. 729-756.

Chae, B.(Kevin) (2014), "A complexity theory approach to IT-enabled services (IESs) and service innovation: business analytics as an illustration of IES”, Decision Support Systems, Vol. 57, pp. 1-10. 
ITP 34,6

Chana, F.T.S. and Chong, A.Y.L. (2013), "Determinants of mobile supply chain management system diffusion: a structural equation analysis of manufacturing firms", International Journal of Production Research, Taylor \& Francis, Vol. 51 No. 4, pp. 1196-1213.

Chen, D.Q., Preston, D.S. and Swink, M. (2015), "How the use of big data analytics affects value creation in supply chain management", Journal of Management Information Systems, Taylor \& Francis, Vol. 32 No. 4, pp. 4-39.

Chen, H., Chiang, R.H. and Storey, V.C. (2012), "Business intelligence and analytics: from big data to big impact”, MIS Quarterly: Management Information Systems, Vol. 36 No. 4, pp. 1165-1188, Management Information Systems Research Center, University of Minnesota.

Cheng, Y.-M. (2020), "Quality antecedents and performance outcome of cloud-based hospital information system continuance intention", Journal of Enterprise Information Management, Vol. 33 No. 3, pp. 654-683.

Chiang, R.H.L., Grover, V., Liang, T.P. and Zhang, D. (2018), "Special issue: strategic value of big data and business analytics", Journal of Management Information Systems, Taylor \& Francis, Vol. 35 No. 2, pp. 383-387.

Collier, K. (2012), Agile Analytics: A Value-Driven Approach to Business Intelligence and Data Warehousing, Addison-Wesley, Boston, MA.

Conboy, K. (2009), "Agility from first principles: reconstructing the concept of agility in information systems development”, Information Systems Research, Vol. 20 No. 3, pp. 329-354, Informs.

Conboy, K., Dennehy, D. and O'Connor, M. (2020), “Big time': an examination of temporal complexity and business value in analytics", Information and Management, Vol. 57 No. 1, p. 103077, doi: $10.1016 /$ j.im.2018.05.010.

Daradkeh, M.K. (2019), "Determinants of visual analytics adoption in organizations", Information Technology and People, Emerald Publishing, Vol. 32 No. 3, pp. 668-695.

Dennehy, D., Pappas, I.O., Samuel, F.W. and Katina, M. (2020), "Special issue: business analytics for the management of information systems development", Information Technology and People, available at: https://www.emeraldgrouppublishing.com/journal/itp/business-analyticsmanagement-information-systems-development.

Elhoseny, M., Kabir Hassan, M. and Kumar Singh, A. (2020), "Special issue on cognitive big data analytics for business intelligence applications: towards performance improvement", International Journal of Information Management, Vol. 50, pp. 413-415.

Fornell, C. and Larcker, D.F. (1981), "Evaluating structural equation models with unobservable variables and measurement error", Journal of Marketing Research, Vol. 18 No. 1, p. 39, Sage Publications Sage CA: Los Angeles, CA.

Fosso Wamba, S., Akter, S., Edwards, A., Chopin, G. and Gnanzou, D. (2015), "How 'big data' can make big impact: findings from a systematic review and a longitudinal case study", International Journal of Production Economics, Elsevier, Vol. 165, pp. 234-246.

Ghobadi, S. and Mathiassen, L. (2016), "Perceived barriers to effective knowledge sharing in agile software teams", Information Systems Journal, Wiley Online Library, Vol. 26 No. 2, pp. 95-125.

Ghobadi, S. and Mathiassen, L. (2017), "Risks to effective knowledge sharing in agile software teams: a model for assessing and mitigating risks", Information Systems Journal, Wiley Online Library, Vol. 27 No. 6, pp. 699-731.

Gregory, R.W., Beck, R. and Keil, M. (2013), "Control balancing in information systems development offshoring projects", MIS Quarterly: Management Information Systems, Vol. 37 No. 4, pp. 1211-1232.

Griva, A., Byrne, S., Dennehy, D. and Conboy, K. (2020), "Software requirements quality: using analytics to challenge assumptions at Intel", IEEE Software. doi: 10.1109/MS.2020.3043868.

Gupta, A., Yousaf, A. and Mishra, A. (2020), "How pre-adoption expectancies shape post-adoption continuance intentions: an extended expectation-confirmation model", International Journal of Information Management, Vol. 52, p. 102094. 
Hair, J.F., Sarstedt, M., Hopkins, L. and Kuppelwieser, V.G. (2014), "Partial least squares structural equation modeling (PLS-SEM): an emerging tool in business research", European Business Review, Springer Heidelberg, Vol. 26 No. 2, pp. 106-121.

Hair, J.F. Jr, Hult, G.T.M., Ringle, C. and Sarstedt, M. (2016), A Primer on Partial Least Squares Structural Equation Modeling (PLS-SEM), Sage Publications, California.

Hair, J.F. Jr, Matthews, L.M., Matthews, R.L. and Sarstedt, M. (2017), "PLS-SEM or CB-SEM: updated guidelines on which method to use", International Journal of Multivariate Data Analysis, Inderscience Publishers (IEL), Vol. 1 No. 2, p. 107.

Hassan, N.R. and Mathiassen, L. (2018), "Distilling a body of knowledge for information systems development”, Information Systems Journal, Wiley-Blackwell, Vol. 28 No. 1, pp. 175-226.

Jaklič, J., Grublješič, T. and Popovič, A. (2018), "The role of compatibility in predicting business intelligence and analytics use intentions", International Journal of Information Management, Vol. 43, pp. 305-318.

Jenkin, T.A., Chan, Y.E. and Sabherwal, R. (2019), "Mutual understanding in information systems development: changes within and across projects", Management Information Systems Quarterly, Society for Information Management and The Management Information Systems, Vol. 43 No. 2, pp. 649-671.

Kautz, K. (2011), "Investigating the design process: participatory design in agile software development", Information Technology and People, Emerald Group Publishing, Vol. 24 No. 3, pp. 217-235.

Kisielnicki, J. and Misiak, A.M. (2016), "Effectiveness of agile implementation methods in business intelligence projects from an end-user perspective", Informing Science, Vol. 19 No. 1, pp. 161-172.

Kitchens, B., Dobolyi, D., Li, J. and Abbasi, A. (2018), "Advanced customer analytics: strategic value through integration of relationship-oriented big data", Journal of Management Information Systems, Taylor \& Francis, Vol. 35 No. 2, pp. 540-574.

Klaus, S. (2019), "The global competitiveness report", available at: http://www3.weforum.org/docs/ WEF_TheGlobalCompetitivenessReport2019.pdf.

Krishnamoorthi, S. and Mathew, S.K. (2018), "Business analytics and business value: a comparative case study", Information and Management, Vol. 55 No. 5, pp. 643-666.

Larson, D. (2019), "A review and future direction of business analytics project delivery", Aligning Business Strategies and Analytics, Springer, Cham, pp. 95-114.

Larson, D. and Chang, V. (2016), "A review and future direction of agile, business intelligence, analytics and data science", International Journal of Information Management, Vol. 36 No. 5, pp. 700-710.

Leguina, A. (2015), "A primer on partial least squares structural equation modeling (PLS-SEM)", International Journal of Research and Method in Education, Sage publications, Vol. 38, doi: 10. 1080/1743727x.2015.1005806.

Liu, Y., Han, H. and DeBello, J. (2018), “The challenges of business analytics: successes and failures", Proceedings of the 51st Hawaii International Conference on System Sciences. doi: 10.24251/hicss. 2018.105 .

Mandal, S. (2019), "The influence of big data analytics management capabilities on supply chain preparedness, alertness and agility: an empirical investigation”, Information Technology and People, Emerald Publishing, Vol. 32 No. 2, pp. 297-318.

McAvoy, J., Nagle, T. and Sammon, D. (2013), "Using mindfulness to examine ISD agility", Information Systems Journal, Wiley-Blackwell, Vol. 23 No. 2, pp. 155-172.

Mikalef, P., Boura, M., Lekakos, G. and Krogstie, J. (2019), "Big data analytics and firm performance: findings from a mixed-method approach", Journal of Business Research, Vol. 98, pp. 261-276. 
ITP 34,6

Mikalef, P., Pappas, I.O., Krogstie, J. and Pavlou, P.A. (2020), "Big data and business analytics: a research agenda for realizing business value”, Information and Management, Vol. 57 No. 1, p. 103237.

Nam, D., Lee, J. and Lee, H. (2019a), "Business analytics adoption process: an innovation diffusion perspective”, International Journal of Information Management, Vol. 49, pp. 411-423.

Nam, D., Lee, J. and Lee, H. (2019b), "Business analytics use in CRM: a nomological net from IT competence to CRM performance", International Journal of Information Management, Vol. 45, pp. 233-245.

Öbrand, L., Augustsson, N.P., Mathiassen, L. and Holmström, J. (2019), "The interstitiality of IT risk: an inquiry into information systems development practices", Information Systems Journal, Wiley Online Library, Vol. 29 No. 1, pp. 97-118.

Ochara, N.M., Kandiri, J. and Johnson, R. (2014), "Influence processes of implementation effectiveness in challenged information technology projects in Africa", Information Technology and People, Emerald Group Publishing, Vol. 27 No. 3, pp. 318-340.

Persaud, A. (2020), "Key competencies for big data analytics professions: a multimethod study", Information Technology and People, Emerald Publishing Limited, Vol. 34 No. 1, pp. 178-203, doi: 10.1108/ITP-06-2019-0290.

Pinsonneault, A. and Kraemer, K.L. (1993), "Survey research methodology in management information systems: an assessment", Journal of Management Information Systems, Taylor \& Francis, Vol. 10 No. 2, pp. 75-105.

Podsakoff, P.M., MacKenzie, S.B., Lee, J.Y. and Podsakoff, N.P. (2003), "Common method biases in behavioral research: a critical review of the literature and recommended remedies", Journal of Applied Psychology, American Psychological Association, Vol. 88 No. 5, pp. 879-903.

Reinartz, W., Haenlein, M. and Henseler, J. (2009), "An empirical comparison of the efficacy of covariance-based and variance-based SEM", International Journal of Research in Marketing, Elsevier, Vol. 26 No. 4, pp. 332-344.

Rossi, B., Russo, B. and Succi, G. (2012), "Adoption of free/libre open source software in public organizations: factors of impact”, Information Technology and People, Emerald Group Publishing, Vol. 25 No. 2, pp. 156-187.

Saba, M., Bou Saba, P. and Harfouche, A. (2018), "Hidden facets of IT projects are revealed only after deployment: the case of French agricultural cooperatives", Information Technology and People, Emerald Group Publishing, Vol. 31 No. 1, pp. 239-255.

Seddon, P.B., Constantinidis, D., Tamm, T. and Dod, H. (2017), "How does business analytics contribute to business value?", Information Systems Journal, Wiley-Blackwell, Vol. 27 No. 3, pp. 237-269.

Shah, S., Gochtovtt, A. and Baldini, G. (2019), "Importance of project management in business analytics: academia and real world", Aligning Business Strategies and Analytics, Springer, pp. 81-94.

Stodder, D. (2013), Achieving Greater Agility with Business Intelligence, TDWI Best Practices Report First Quarter, pp. 1-40.

Szajna, B. and Scamell, R.W. (1993), "The effects of information system user expectations on their performance and perceptions", Management Information System Quarterly, Vol. 17 No. 4, pp. 493-516.

Taylor, K.J. (2016), “Adopting Agile software development: the project manager experience", Information Technology and People, Emerald Group Publishing, Vol. 29 No. 4, pp. 670-687.

Torres, R., Sidorova, A. and Jones, M.C. (2018), "Enabling firm performance through business intelligence and analytics: a dynamic capabilities perspective", Information and Management, Vol. 55 No. 7, pp. 822-839.

Tripp, J.F., Riemenschneider, C. and Thatcher, J.B. (2016), "Job satisfaction in agile development teams: agile development as work redesign", Journal of the Association for Information Systems, Vol. 17 No. 4, pp. 267-307. 
Tsoy, M. and Staples, D.S. (2020), "What are the critical success factors for agile analytics projects?", Information Systems Management, Vol. 32, pp. 1-18, doi: 10.1080/10580530.2020.1818899.

Um, S., Chon, K. and Ro, Y.H. (2006), “Antecedents of revisit intention”, Annals of Tourism Research, Vol. 33 No. 4, pp. 1141-1158.

Venkatesh, V., Thong, J.Y.L. and $\mathrm{Xu}$, X. (2012), "Consumer acceptance and use of information technology: extending the unified theory of acceptance and use of technology", MIS Quarterly: Management Information Systems, Vol. 36 No. 1, pp. 157-178, JSTOR.

Viaene, S. and Van Den Bunder, A. (2011), "The secrets to managing business analytics projects", MIT

BA

continuance in agile ISD projects

1569 Sloan Management Review, Massachusetts Institute of Technology, Cambridge, MA, Vol. 53, No. 1, pp. 65-69.

Vidgen, R., Shaw, S. and Grant, D.B. (2017), "Management challenges in creating value from business analytics", European Journal of Operational Research, Vol. 261 No. 2, pp. 626-639.

Wang, S., Yeoh, W., Richards, G., Wong, S.F. and Chang, Y. (2019), "Harnessing business analytics value through organizational absorptive capacity", Information and Management, Vol. 56 No. 7 , p. 103152.

Wang, S.M., Huang, Y.K. and Wang, C.C. (2020), "A model of consumer perception and behavioral intention for AI service”, ACM International Conference Proceeding Series, pp. 196-201.

Werder, K. and Maedche, A. (2018), "Explaining the emergence of team agility: a complex adaptive systems perspective", Information Technology and People, Emerald Publishing, Vol. 31 No. 3, pp. 819-844.

Wixom, B.H., Yen, B. and Relich, M. (2013), "Maximizing value from business analytics", Management Information System Quarterly Executive, Vol. 12, pp. 111-123, Association for Information Systems.

Wu, I.L., Chiu, M.L. and Chen, K.W. (2020), "Defining the determinants of online impulse buying through a shopping process of integrating perceived risk, expectation-confirmation model, and flow theory issues", International Journal of Information Management, Vol. 52, p. 102099.

Xia, W. and Lee, G. (2005), "Complexity of information systems development projects: conceptualization and measurement development", Journal of Management Information Systems, Vol. 22 No. 1, pp. 45-83.

Yi, Y. (1990), “A critical review of consumer satisfaction”, Review of Marketing, American Marketing Association, Chicago, IL, Vol. 4 No. 1, pp. 68-123.

Zheng, L. (2019), "The role of consumption emotions in users' mobile gaming application continuance intention", Information Technology and People, Emerald Publishing, Vol. 33 No. 1, pp. 340-360.

\section{Corresponding author}

Muhammad Ovais Ahmad can be contacted at: ovais.ahmad@kau.se

For instructions on how to order reprints of this article, please visit our website:

www.emeraldgrouppublishing.com/licensing/reprints.htm

Or contact us for further details: permissions@emeraldinsight.com 